\title{
Prevalence of Plantar Fasciitis Among Nurses at a Tertiary Care Centre in a Rural Area: A Cross Sectional Study
}

\section{Komal Santosh Bhoir ${ }^{* 1}$, Vishnu Vardhan G.D ${ }^{2}$.}

${ }^{* 1}$ BPT (Intern), Dr. A.P.J. Abdul Kalam College of Physiotherapy, Pravara Institute of Medical Sciences, Loni, Maharashtra 413736, India.

${ }^{2}$ Associate Professor \& HOD, Dr. A.P.J. Abdul Kalam College of Physiotherapy, Pravara Institute of Medical Sciences, Loni, Maharashtra 413736, India.

\section{ABSTRACT}

Background: The plantar fascia can further encounter a form of pathological degeneration called as plantar fasciitis that is one of the most common causes of heel pain. Plantar fasciitis is a multifactorial in origin and works as a mechanical overloading reaction to multiple instances of microtrauma.

Purpose: This research will rule out the prevalence of plantar fasciitis in nurses both male and female with the help of windlass test and also make us aware about the correlation of plantar fasciitis among males and females.

Methodology: A simple random sampling of 100 healthy nurses, 70 female nurses and 30 male nurses from Pravara Institute, Loni was included. The participants included were between age group of 20-50 years and were screened according to inclusion and exclusion criteria. Windlass test was performed in all the recruited participants. The test was done both in non-weightbearing (NWB) and weightbearing (WB) position. If pain was reproduced, the subject then marked the location of the pain. If pain was provoked then the test was considered positive.

Result: The windlass test (weight bearing and non-weight bearing) showed that out of 100 participants $21 \%$ tested positive; out of which $17 \%$ females and $4 \%$ males responded positive in the study.

Conclusion: The study concluded that female nurses are more prone to develop plantar fasciitis when compared with male nurses.

KEY WORDS: Plantar fascia, Plantar fasciitis, Plantar fascia thickness, Pain, Nurses, Windlass test.

Address for correspondence: Komal Santosh Bhoir, PT., Dr. A.P.J. Abdul Kalam College Of Physiotherapy, Pravara Institute Of Medical Sciences, Loni, Maharashtra 413736, India.

E-Mail: Komal53bhoir@gmail.com

Access this Article online

Quick Response code

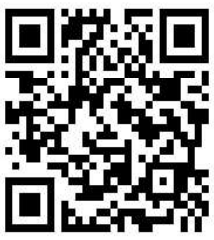

DOI: $10.16965 /$ ijpr.2021.140

Journal Information

International Journal of Physiotherapy and Research

ISSN (E) 2321-1822 | ISSN (P) 2321-8975

https://www.ijmhr.org/ijpr.html

DOI-Prefix: https://dx.doi.org/10.16965/ijpr

\section{Article Information}

Received: 07 May 2021

Peer Review: 09 May 2021

Revised: 22 May 2021
Accepted: 11 Jun 2021

Published (O): 11 Jul 2021

Published (P): 11 Aug 2021

\section{INTRODUCTION}

Surfaces of sole of foot are in following order as- superficial fascia, deep fascia and four layers with neurovascular bundles [1].

Plantar fascia also called as plantar aponeurosis is the deep fascia in the sole of foot [2]. It is a thick band which extends from calcaneal tuberosity to toes. Plantar fascia has three portions, and forms a strong intermuscular septum between the three plantar muscle groups -medial, lateral and central bands from which the central one is the largest band [3].

The plantar fascia can further encounter a form of pathological degeneration called as 
plantar fasciitis [4]. Plantar fasciitis is a self-limiting condition. Plantar fasciitis is a multifactorial in origin and works as a mechanical overloading reaction to multiple instances of microtrauma. It is characterized by pain in the medial plantar area of heel on weight bearing [5]. It is an abnormality or injury at site of attachment of ligament or tendon to bone (origin of plantar fascia at the medial tubercle of the calcaneus). These abnormality causes inflammation of the thick tissue. During static stance and a dynamic function plantar fascia has a prominent role in shock absorption in weight bearing foot. This function of plantar fascia is hampered due to several preliminary factors such as overuse of the fascia from prolonged standing or occupational prolonged weight bearing, rapid increase in activity levels, inadequate stretching, age, excessive foot pronation, trauma to the foot, prolonged periods of walking or running, obesity, improper footwear, hard soles of footwear, also biomechanical disorders like pes planus (flat foot), pes cavus (high arched foot) and tight Achilles tendon, decreased dorsiflexion, repetitive stress [6].

These factors would create pathologic burden over calcaneal insertion of plantar fascia, which may further cause microtears in the fascia that may in the end lead to perifascial oedema and also increased heel pad thickness ensuing in interference of the normal biomechanics of the foot and eventually would lead to decrease in the competence of force absorption. This decrease in force absorption would therefore lead to overstressing of plantar fascia and increase the degenerative changes $[7,8,9]$.

People with plantar fasciitis may present with heel pain with their first steps in the morning, or after long periods of sitting, and also elicit a response of sharp pain with palpation of the medial plantar calcaneal region [10]. Pain is usually worse, early in the morning. Once the patient starts walking, pain tends to reduce. The pain is reduced, but not fully resolved throughout the day, and it is exacerbated by various activities such as prolonged standing or walking. While walking, the foot moves into dorsiflexion. At night, the foot usually falls into plantarflexion position. The plantar fascia minimally contracts in the bed and the initial stretching associated with early morning waking is probably responsible for pain initiation in the morning when the patient alights from the bed [11].

A diagnosis of plantar fasciitis is based on patient's history and physical findings. 'Windlass mechanism' describes the manner by which plantar fascia supports the foot during weight bearing activities and provides information regarding the biomechanical stresses placed on plantar fascia. A windlass is a tightened rope or a cable. Plantar fascia imitates this cable or rope attached to the calcaneus and metatarsophalangeal joints. Dorsiflexion winds the plantar fascia around the head of metatarsal. This winding of plantar fascia shortens the distance between calcaneus and metatarsals, which will increase medial longitudinal arch. The plantar fascia shortening, that results from great toe dorsiflexion is the concentration of windlass mechanism principle. During plantar fasciitis, if toes are passively dorsiflexed (non-weight bearing or weight bearing) and if pain elicits the test is positive [12].

Work-related musculoskeletal disease is a health error, caused by various factors such as repetitive motion, excessive use of forces and are common among nursing professionals. The nursing profession, which is responsible for directly offering healthcare service to subjects, is physically and psychologically demanding [13]. Nurses spend a load of time on their feet. Our feet have the capacity to carry three times our body-weight with each step. Nursing duty requires a strenuous job duty, that is lifting subjects, lifting equipments, running to a code. Also, most of the work requires prolonged standing and walking, the weight bearing is also on hard surfaces- hospital floors, concrete stairs- this unrelenting surface does not help much to improve the shock absorption of footsteps $[14,15]$.

Plantar fascia and heel fat pad stiffness are generally similar in both genders; however, females have a lower plantar fascia and heel fat pad thickness compared with males. Studies suggest that higher plantar fascia and heel fat pad thickness in males may be related 
to higher body mass and height $[16,17,18]$.

The occurrence of plantar fasciitis is usually associated with work-related prolonged weight bearing, which is like an everyday thing in nurses. Due to this hectic work, nurses are very much prone to get plantar fasciitis. However, very few researches focus on the differences between male and female nurses affected by the same. The need of this research is to find out the prevalence of plantar fasciitis in nurses and also to correlate the presence of plantar fasciitis among males and females. The main purpose was to evaluate the presence of plantar fasciitis with the help of windlass test.

\section{METHODS}

The Ethical clearance was obtained from Institutional Ethical committee (PIMS/ DR.APJAKCOPT/IEC/2020/09). The study is a cross-sectional type with simple random sampling. The methodology details are shown in Table no.1. The aim and objectives were made clear to every participant performing the test. The informed consent was taken from the participant regarding the procedure prior to the study. The consent form included participants declaration, right to withdrawal and also confidentiality of the details. After this, a brief screening performa was taken, in which participants were screened according to inclusion and exclusion criteria as mentioned in Table no. 2. Figure no.1 represents the Flow Chart depicting the process of screening and recruitment of nurses.

Hundred adult subjects from Pravara Rural Hospital, 70 females and 30 males with age criteria between 20 to 50 years participated in the study. These subjects were tested in the examination room.

The next step was to perform 'Windlass test' both in non-weight bearing (NWB) and weight bearing (WB) positions.

First, the test was done in NWB position (as demonstrated in figure no. 2). To achieve this position, subjects were asked to sit upright on a plinth or chair in a figure of four pattern, that is their one leg crossed over the other (90-degree knee flexion). The investigator then stabilized the ankle in neutral position with one hand, and grasped the proximal segment of great toe with the other hand. The interphalangeal joint of the great toe was allowed to flex, so that the hallucis longus muscle would not restrict the joint. The investigator then passively extended the first metatarsophalangeal joint to end range or until the subject experienced pain, vice versa. If pain was reproduced, the subject then marked the location of the pain. If pain was provoked at end range of passive extension then the test was considered positive.

Next, the Windlass test was performed in WB position (as demonstrated in figure no.3). In this, the subject was asked to step on a step-stool or a stair in such a manner that their toes were hanging over the edge of the stool and the metatarsal heads were supported on the stool, but there was no interruption in the motion of 1st metatarsophalangeal joint. Subjects were instructed to place equal weight on their feet. The researcher then passively extended the 1st metatarsophalangeal joint. If pain was provoked then the test was considered positive.

Table 1: Methodology details.

\begin{tabular}{l}
\hline Source of Data \\
The source of data will be collected from Nurses working under \\
Pravara Institute of Medical Sciences, Loni \\
Study Setting \\
Pravara Rural Hospital, Loni \\
Duration of study \\
6 months \\
Method of Data collection \\
Data will be primarily collected by the principal investigator \\
Type of Study \\
Descriptive study \\
Study design \\
Cross sectional and comparative study \\
Sample Size \\
100 \\
Participants \\
Nurses \\
Sampling method \\
Simple Random Sampling method \\
\hline
\end{tabular}

Table 2: Inclusion and Exclusion Criteria.

\begin{tabular}{|c|c|}
\hline Inclusion Criteria & Exclusion Criteria \\
\hline $\begin{array}{l}\text { Those who have filled the consent } \\
\text { form }\end{array}$ & Any trauma to the foot \\
\hline $\begin{array}{l}\text { Service delivering nurses } \\
\text { (ward/outpatient/operating room or } \\
\text { intensive care units) }\end{array}$ & Educators or students \\
\hline Work shift -day/night 8-12 hours & $\begin{array}{l}\text { Subjects with recent surgical history } \\
\text { around foot or leg }\end{array}$ \\
\hline BMI- 18-24.9 & Limb Length Discrepancy \\
\hline Men and women & Any musculoskeletal deformity of foot/leg \\
\hline Age group of $20-50$ years & Neurological deficit \\
\hline
\end{tabular}


Fig. 1: Flow Chart.

Flow Diagram

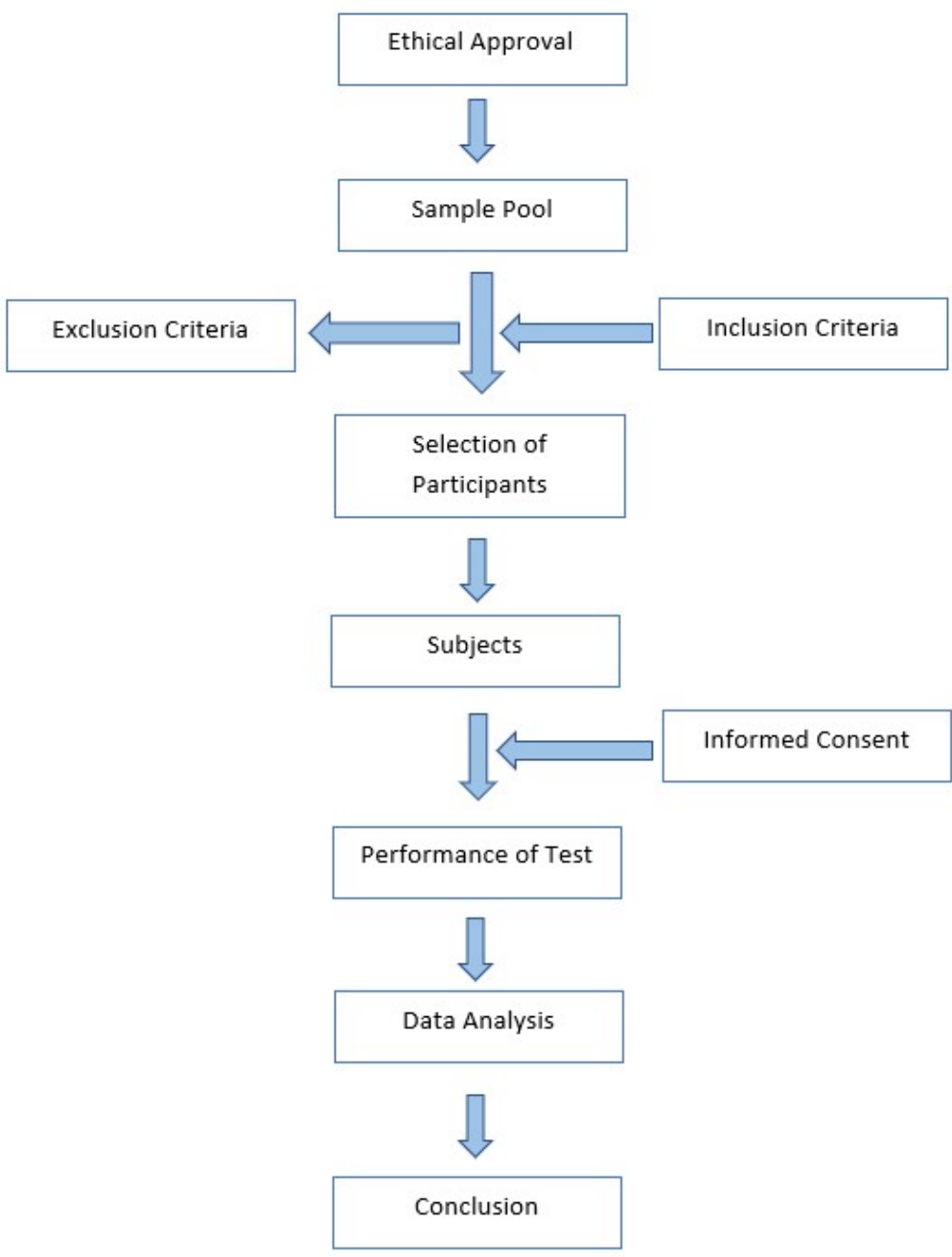

\section{RESULTS}

The study included nurses with 70 females and 30 males with $\mathrm{BMI}$ ranging from 18 to 24.9 i.e., average BMI of 21.4593 .

$21 \%$ nurses were tested positive, while $79 \%$ nurses were tested negative out of total population when performed Windlass test as demonstrated in graph no. 01.

Out of total positive population $(n=21)$, total females positive were $80.95 \%$ i.e. $(n=17)$, while total males positive were $19.05 \%$ i.e. $(n=4)$ as demonstrated in graph no. 02.

Out of 17 female nurses positive, $76.47 \%$ female nurses $(n=13)$ were tested positive in both WB and NWB position; while the remaining $23.53 \%$ female nurses $(n=4)$ were tested positive only in WB position and negative in NWB position. Also, out of 4 male nurses positive, $75 \%$ male nurses $(n=3)$ were tested positive in both WB and NWB position; while the remaining $25 \%$ male nurse $(n=1)$ was tested positive only in WB position and negative in NWB position when performed Windlass test as demonstrated in graph no. 03.

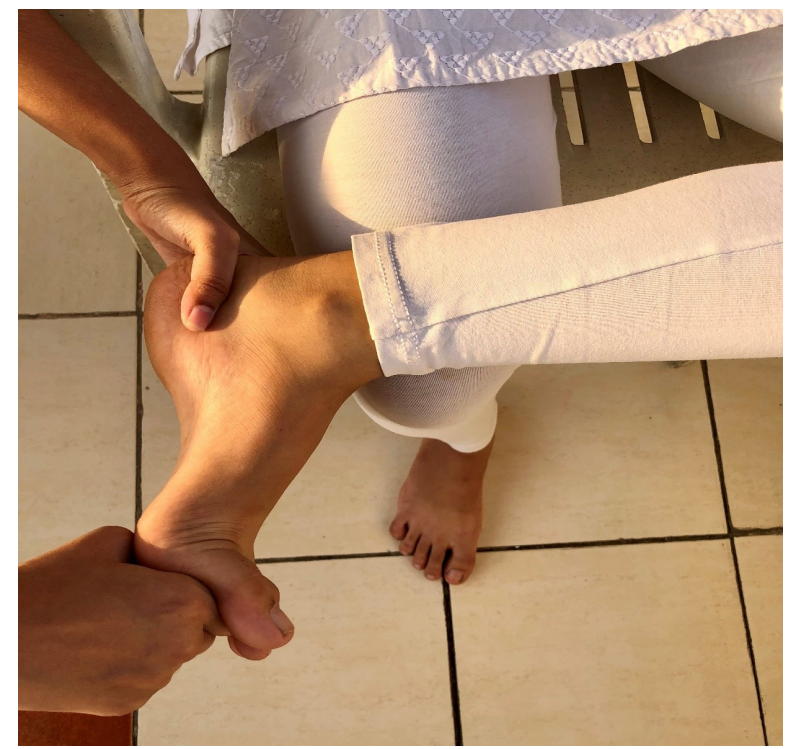

Fig. 2: Windlass test performed in non-weight bearing position. 


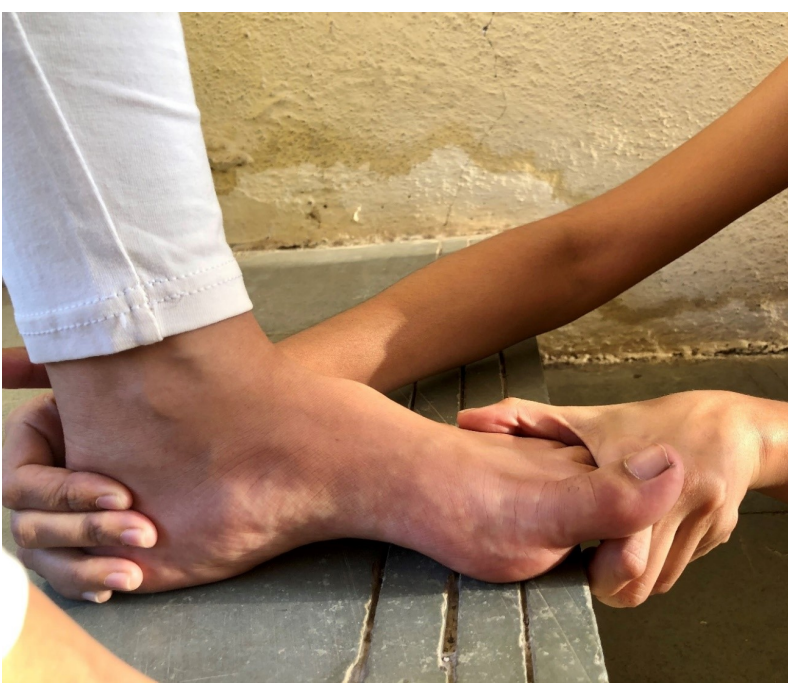

Fig. 3: Windlass test performed in Weight bearing position.

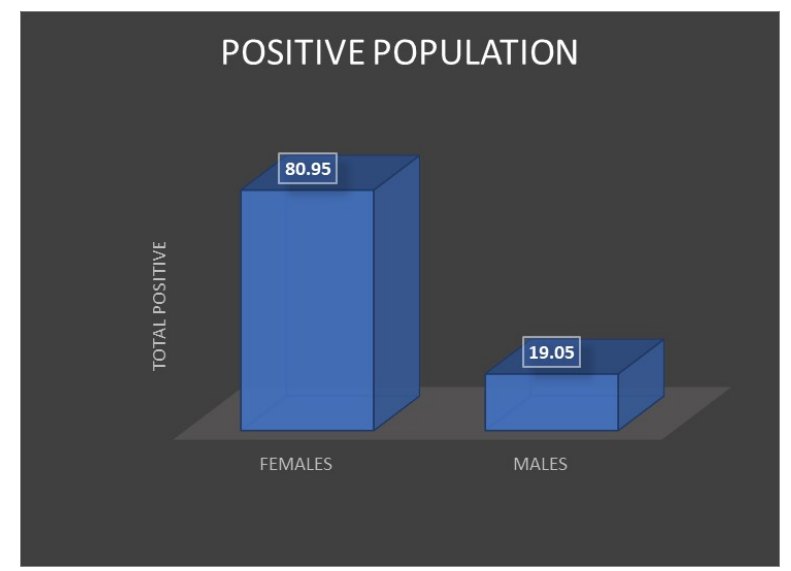

Graph 2: Comparison between percentage of positive Windlass test in females and males

\section{DISCUSSION}

The Windlass test as described in this article, is the only specific test for diagnosing plantar fasciitis. All the subjects in this study received a diagnosis of plantar fasciitis by performing Windlass test in both the positions i.e., WB and NWB with tenderness localized to the medial calcaneal tubercle. Sensitivity refers to a test's ability to state an individual with the condition or disease as positive. A highly sensitive test means there are few false negative results, and thus fewer cases of disease are missed. The specificity of a test is its ability to state an individual who does not have a particular condition or disease as negative. Regardless of a $100 \%$ specificity for a positive Windlass test clashing with the diagnosis of plantar fasciitis i.e., all the subjects who were positive with Windlass test had plantar fasciitis, the sensitivity of Windlass test was quite higher in WB position when compared with NWB position. Since an

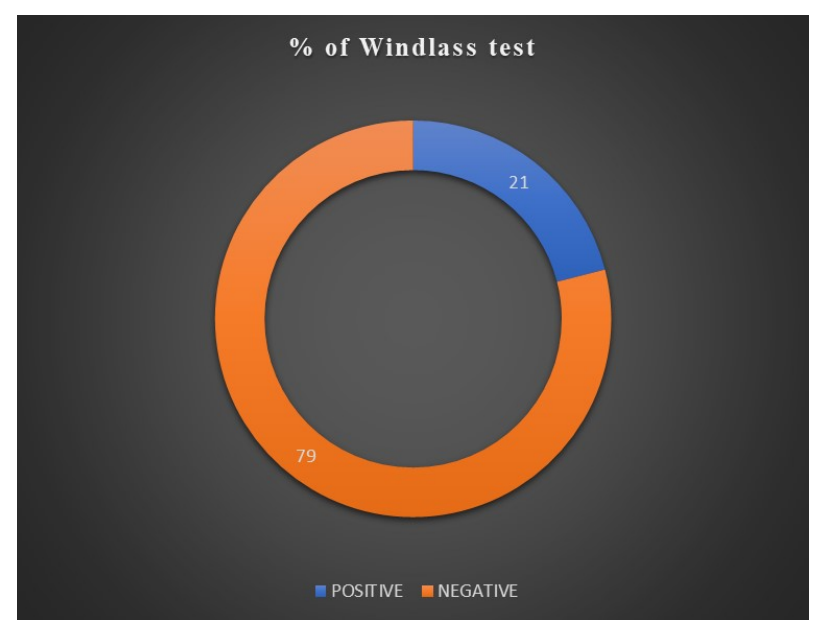

Graph 1: Percentage of Windlass test

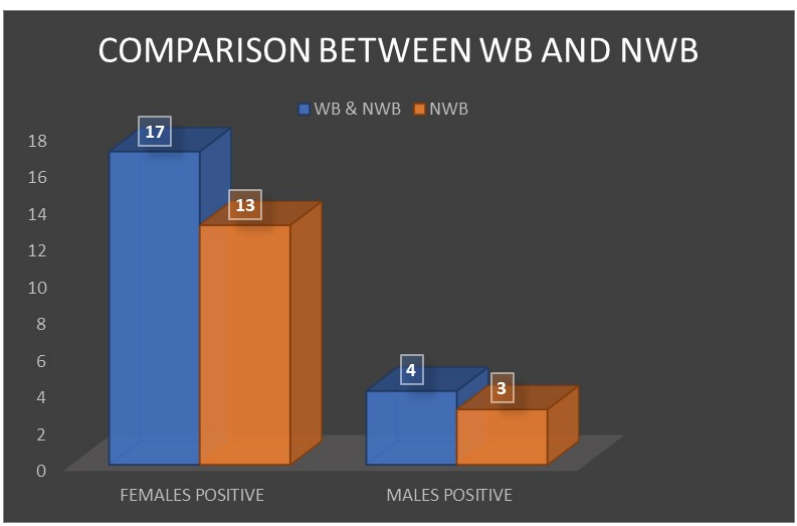

Graph 3: Comparison between positive Weight-bearing and Non-weight bearing (Windlass test) in both male and female nurses.

inflamed, tender structure is stretched, while performing Windlass test as the test does increase the tension in the plantar fascia, one might expect a high degree of sensitivity for this test. The justification for the lower sensitivity for the Windlass test may have been due to the timing of the test. Most of the subjects with plantar fasciitis report pain upon getting out of bed in the morning which subsides as the patient walks, after prolonged weightbearing on their feet such as at the end of the day and/or weightbearing after prolonged sitting. This study did not control for the time of day when the subjects were evaluated. Although it is possible to have a misdiagnosis in some of the subjects in the plantar fasciitis group [19].

This research focuses on the fact that who are prone to develop plantar fasciitis with the help of Windlass test. The Windlass test (WB and NWB) showed that out of 100 participants $21 \%$ 
tested positive; out of which 17 females and 4 males responded positive in the study. Out of these 17 females that were positive, 13 females showed positive test in NWB position and out of 4 males that were positive, only 3 males showed positive test in NWB position. Hence, through this research we find out that the chances are high for female nurses to develop plantar fasciitis when compared with male nurses. The female nurses who responded negative to the test are not prone to develop but can develop plantar fasciitis as it is clinically stated that females are prone to develop plantar fasciitis. So, it is of much importance to take proper care of the sole. Nurses are constantly on their feet throughout the day, because of the job they are into, which puts them in a hectic environment which can in the end direct them towards inflammation in the tissue i.e., plantar fascia and cause the bone and tissue to constantly irritate each other. As the plantar fascia deteriorates, it may further give rise to heel pain because the fascia will then be no longer efficiently be able to protect the underneath bone. Hence, the plantar fascia is crucial for the foot health. If this fascia is injured, it is very much necessary to safely rehabilitate it to its $100 \%$. Even an inflammation of a small degree will cause it to rub against the bone and may cause a long-term irritation. Since nurses doesn't get much time to rest and are on their feet for a long time, there are high chances of the fascia to get irritated. This study will make the nurses aware about the occurrence and risks of developing plantar fascia so that they consciously try to prevent it and let it be better. This injury to the fascia can happen due to various factors but sometimes it's not these factors but the overall lifestyle one lives. Through this research we can rule out that nurses who are prone to develop plantar fasciitis, should modify their activities according to standing hours of the occupation.

\section{CONCLUSION}

The present study concluded that female nurses are more prone to develop plantar fasciitis when compared with male nurses. Also, there are getter chances of Windlass test to be positive in WB position than NWB position.

\section{ABBREVATIONS}

BMI - Body Mass Index

NWB - Non-weight bearing

WB - Weight bearing

\section{ACKNOWLEDGEMENTS}

It is my privilege to express my sincere gratitude to Dr. Vishnu Vardhan for his valuable guidance, timely and scholarly advice.

\section{Conflicts of interest: None}

\section{REFERENCES}

[1]. Chaurasia BD. BD Chaurasia's Human Anatomy Regional and Applied, Dissection and Clinical, Volume 2: Edition 6: Lower Limb, Abdomen and Pelvis. CBS publishers and Distributors Pvt Ltd.

[2]. Drake LR, Mitchell A, Vogl AW. Gray's Anatomy for Students. Third Edition: Churchill Livingstone, Elsevier Inc publishers.

[3]. Joshi J, Kotwal P. Essentials of Orthopaedics and Applied Physiotherapy. Third Edition: Elsevier publishers.

[4]. Stecco C, Corradin M, Macchi V, Morra A, Porzionato A, Biz C, De Caro R. Plantar fascia anatomy and its relationship with $A$ chilles tendon and paratenon. Journal of anatomy. 2013 Dec;223(6):665-76.

[5]. Gutteck N, Schilde S, Delank KS. Pain on the plantar surface of the foot. Deutsches Ärzteblatt International. 2019 Feb;116(6):83.

[6]. Pallavi S, Yamini S, Megha Y, Jyoti S, Mangalam K, Sakshi A. To Compare the Prevalence of Plantar Fasciitis among Females Wearing Flat Foot Wear and Heels in Young Adults. Website: www. ijpot. com. 2020 Apr;14(02):2177.

[7]. Erdemir A, Hamel AJ, Fauth AR, Piazza SJ, Sharkey NA. Dynamic loading of the plantar aponeurosis in walking. JBJS. 2004 Mar 1;86(3):546-52.

[8]. Granado MJ, Lohman III EB, Daher NS, Gordon KE. Effect of Gender, Toe Extension Position, and Plantar Fasciitis on Plantar Fascia Thickness. Foot \& ankle international. 2019 Apr;40(4):439-46.

[9]. Sung KC, Chung JY, Feng IJ, Yang SH, Hsu CC, Lin HJ, Wang JJ, Huang CC. Plantar fasciitis in physicians and nurses: a nationwide population-based study. Industrial health. 2020;58(2):153-60.

[10]. Goff JD, Crawford R. Diagnosis and treatment of plantar fasciitis. American family physician. 2011 Sep 15;84(6):676-82.

[11]. Cutts S, Obi N, Pasapula C, Chan W. Plantar fasciitis. The Annals of The Royal College of Surgeons of England. 2012 Nov;94(8):539-42.

[12]. Bolgla LA, Malone TR. Plantar fasciitis and the windlass mechanism: a biomechanical link to clinical practice. Journal of athletic training. 2004 Jan;39(1):77. 
[13]. Scher CD, Belmont Jr LC, Bear MR, Mountcastle SB, Orr JD, Owens MB. The incidence of plantar fasciitis in the United States military. JBJS. 2009 Dec 1;91(12):2867-72.

[14]. Stolt M, Suhonen R, Kielo E, Katajisto J, Leino Kilpi $H$. Foot health of nurses-A cross sectional study. International Journal of Nursing Practice. 2017 Aug;23(4): e12560.

[15]. Chiu MC, Wang MJ. Professional footwear evaluation for clinical nurses. Applied Ergonomics. 2007 Mar 1;38(2):133-41.

[16]. Huerta JP, García JM. Effect of gender, age and anthropometric variables on plantar fascia thickness at different locations in asymptomatic subjects. European journal of radiology. 2007 Jun 1;62(3):449-53.
[17]. Taㅇ S. Effect of gender on mechanical properties of the plantar fascia and heel fat pad. Foot \& ankle specialist. 2018 Oct;11(5):403-9.

[18]. Palomo-López P, Becerro-de-Bengoa-Vallejo R, LosaIglesias ME, Rodríguez-Sanz D, Calvo-Lobo C, LópezLópez D. Impact of plantar fasciitis on the quality of life of male and female patients according to the Foot Health Status Questionnaire. Journal of pain research. 2018; 11:875.

[19]. De Garceau D, Dean D, Requejo SM, Thordarson DB. The association between diagnosis of plantar fasciitis and Windlass test results. Foot \& ankle international. 2003 Mar;24(3):251-5.

How to cite this article:

Komal Santosh Bhoir, Vishnu Vardhan G.D. Prevalence of plantar fasciitis among nurses at a tertiary care centre in a rural area- $A$ cross sectional study. Int J Physiother Res 2021;9(4):3900-3906. DOI: 10.16965/ ijpr.2021.140 